\title{
A GESTÃO DE RECURSOS HÍDRICOS NO BRASIL E OS COMITÊS DE BACIAS HIDROGRÁFICAS - A EXPERIÊNCIA DO CBH-MIRANDA (MS)
}

\author{
THE MANAGEMENT OF WATER RESOURCES IN BRAZIL \\ AND THE COMMITTEES OF RIVER BASIN - \\ THE EXPERIENCE OF CBH-MIRANDA (MS)
}

\section{LA GESTIÓN DE LOS RECURSOS HÍDRICOS EN BRASIL Y LOS COMITÉS DE CUENCAS HIDROGRÁFICAS - COMITÉ DE LA CUENCA HIDROGRÁFICA DEL RÍO MIRANDA (MS)}

\section{Edvaldo Cesar Moretti}

Doutorado em Geografia pela Universidade Estadual Paulista - Rio Claro. Professor na Faculdade de Ciências Humanas da Universidade Federal da Grande Dourados (UFGD). Professor permanente do Programa de Pós-graduação em Geografia (Mestrado e Doutorado da UFGD. Pós-doutorado no curso de Geografia do Instituto de Geociências da UNICAMP. Coordenador do Grupo de Pesquisa Território e Ambiente

Universidade Federal da Grande Dourados, Faculdade de Ciências Humanas, Rodovia DouradosItahum, km12, Cidade Universitária. 79825-070 - Dourados-MS

E.mail:emoretti@hotmail.com

\section{Vera Lúcia Freitas Marinho}

Doutoranda em Geografia pelo Programa de Pós-Graduação em Geografia do Instituto de Geociências da Universidade Estadual de Campinas. Docente da Universidade Estadual de Mato Grosso do Sul. E.mail:marinho_vera@yahoo.com.br>

\section{RESUMO}

O artigo tem por tema a gestão dos recursos hídricos explanando sobre a instituição dos comitês de bacias hidrográficas. No Brasil, os comitês são considerados como experiências em processo de consolidação, consistem em colegiados locais, criados nos rios de domínio da União e Estados cujas atribuições devem ser exercidas na bacia hidrográfica de sua jurisdição, possuem a competência de promover o debate, intervir, arbitrar e resolver os conflitos em primeira instância entre usuários, sociedade civil e poder público, no que diz respeito às questões relacionadas com os recursos hídricos.O artigo tem por objetivotratar sobre a experiência do Comitê de Bacia Hidrográfica do Rio Miranda (CBH-Miranda),instituído no ano de 2005, no Mato Grosso do Sul, e pretende contribuir para a reflexão acerca do significado da instituição e o papel efetivo dos comitês de bacias hidrográficas na gestão dos recursos hídricos.

Palavras-chave: recursos hídricos; gestão de bacia hidrográfica; comitê de bacia hidrográfica do rio Miranda. 


\begin{abstract}
The paper has the topic the water management resources explaining about the establishment of watershed committees. In Brazil, the committees are considered as experiences under consolidation, consisting of local boards, created in the Union and States' rivers, whose powers should be exercised in the catchment area of their jurisdiction, have the power to promote debate, intervene, arbitrate and resolve disputes in the first instance between users, civil society and public authorities, with regard to issues related to water resources. The paper has the purpose the experience of the Basin Committee of Rio Miranda (CBH-Miranda), established in 2005 in Mato Grosso do Sul, and aims to contribute about the reflection on the meaning of the institution and the role effective river basin committees in the water management resources.
\end{abstract}

Keywords: watershed management; management of river basins; basin committee of rio Miranda

\title{
RESUMEN
}

1 artículo tiene por tema la gestión de los recursos hídricos explanando sobre las instituciones de los comités de cuencas hidrográficas. En Brasil, estos comités son considerados como una experiencia importante en el proceso de consolidación, consisten en colegiados locales, creados en los ríos de dominio Federal y Estatal, cuyas atribuciones deben ser ejercidas en la cuenca hidrográfica de su jurisdicción, tienen la competencia de promover el debate, intervenir, arbitrar y solucionar los conflictos en primera instancia entre los usuarios, la sociedad civil y el poder público, con respecto a las cuestiones relacionadas con los recursos hídricos. El artículo es el resultado de la investigación realizada sobre la creación de los Comités de Cuencas Hidrográficas, con el ejemplo del Comité de la Cuenca Hidrográfica del río Miranda (CBH-Miranda), creado en el año 2005, en Mato Grosso do Sul, y pretende contribuir para la reflexión acerca del significado de esta institución y el papel efectivo de los comités de cuencas hidrográficas y la gestión de los recursos hídricos.

Palabras claves: recursos hídricos; gestión de cuencas hidrográficas; Comité de la Cuenca Hidrográfica del río Miranda

\section{INTRODUÇÃO}

No Brasil, a partir da segunda metade do século XX, pode ser identificado um processo de reorientação da gestão dos recursos hídricos enquanto política de Estado cujos destaques tratam sobre a importância da água nesse milênio e a implementação do arcabouço legal do sistema de gerenciamento de recursos hídricos, conforme previsto no art. 21 da Constituição federal de 1988 e instituído na Lei federal $n^{\circ}$ 9.433, de 8 de janeiro de 1997 - a Lei das Águas -, que dispõe sobre a Política Nacional de Recursos Hídricos e cria o Sistema Nacional Gerenciamento de Recursos Hídricos (BRASIL, 1997). cria 
Na referida lei estão previstas as premissas da gestão descentralizada, integrada e participativa.Considerando tais prioridades foram estabelecidas as bases necessárias para a implementação de uma política pública de recursos hídricos no país cujas metas visam, entre outras, instituir os instrumentos jurídicos e político-institucionais voltados ao gerenciamento dos recursos hídricos; instituir os comitês de bacias hidrográficas - em âmbito federal e dos estados (MAGALHÃES JÚNIOR, 2007).

Os comitês consistem em órgãos colegiados consultivos, deliberativos e normativos no que se referemàs questões relacionadas à gestão dos recursos hídricos das respectivas bacias hidrográfica nos quais foram criados. Os comitês possuem na base da sua estrutura organizacional a participação do poder público, sociedade civil e setores de usuários das águas. No estado de Mato Grosso do Sul a criação e competência desses colegiados está disciplina na Lei estadual nº 2.406/2002 (MATO GROSSO DO SUL, 2002).

Ao ponderar sobre o processo de consolidação desses colegiados, o artigo visa contextualizar a experiência sul-mato-grossense do Comitê de Bacia Hidrográfica do Rio Miranda - CBH-Miranda, instalado no ano de 2005, e visa compreender e ampliar o olhar sobre a efetivação do papel desse órgão colegiado na gestão dos recursos hídricos no âmbito da respectiva bacia hidrográfica, contribui no exercício de refletir e instigar o debate acadêmico, como também de profissionais interessados sobre o tema abordado.

$\mathrm{O}$ artigo possui o foque teórico-conceitual cujo tema vem se desdobrando nas mais distintas áreas de conhecimento as quais, entre outros profissionais, atuam agentes públicos e privados. Além desses, tem manifestado interesses de pesquisadores, organismos internacionais e instituições envolvidas na definição de prioridades e fomentos de políticas públicas de recursos hídricos.

Por tais razões não há um método único, trata-se da busca em adotar procedimentos metodológicos de investigação pragmática, fundamentada em uma razão cartesiana, com respostas prontas e lineares, ao contrário, optou-se por referências de leituras que concebem o conhecimento como um processo em construção e, portanto, não linear e/ou pronto e acabado (FERRAZ, 2007).

Este estudo foi realizado junto ao Comitê de Bacia Hidrográfica do Rio Miranda, sendo essa experiência significativa por ser o primeiro comitê de bacia hidrográfica criado no estado de Mato Grosso do Sul, no ano de 2005.

Os procedimentos metodológicos adotados consistiram nas seguintes etapas: levantamento e leitura de bibliografia específica sobre o tema, artigos publicados em 
revistas científicas e relatórios oficiais elaborados pelos órgãos técnicos do governo federal e estadual, entre esses a Agência Nacional das Águas (ANA) e o Instituto de Meio Ambiente de Mato Grosso do Sul (IMASUL) ${ }^{1}$; e os trabalho de campo realizado entre 2011 até 2014. Nesse período,por meio do acompanhamento e da participação em reuniões públicas, assembleias ordinárias e nas demais atividades do CBH-Miranda, buscou-se coletar dados, informações e registros de imagens, bem como compartilhar as experiências com os atoresenvolvidos nas práticas da gestão participativa desse colegiado.

Contextualização da instituição dos comitês de bacias hidrográficas no Brasil

No Brasil,nas duas últimas décadas foi cenário de significativas reformulações institucionais dos procedimentos de gestão de recursos hídricos. De acordo com Ioris (2013), tais mudanças vêm promovendo uma concepção de gestão de águas a qual enfatiza o espaço bacia hidrográfica como unidade de intervenção.

Nesse contexto, a instituição dos comitês de bacia hidrográfica é considera uma experiência recente e em processo de consolidação (DI MAURO, et. al 2012). De modo geral, as iniciativas resultaram de um conjunto de reformas adotadas a partir das referências e experiências internacionais de gerenciamento de recursos hídricos, postas em prática desde a década de 1960, em países como: Estados Unidos, França, Alemanha e Inglaterra (MIRANDA, 2006, MAGALHÃES JÚNIOR, 2007, BERRETA, 2013).

Esses colegiados são inspirados em um modelo de gestão integrado, descentralizado e participativo cujas iniciativas objetivam a modernização dos sistemas nacionais de gerenciamento dos recursos hídricos, iniciados na década de 1990, que passam a incorporar o princípio da subsidiariedade cujo processo de tomada de decisões flui em diferentes escalas espaciais, desde o nível federal aos níveis locais -tão próximo quanto possível do cidadão -, nesses casos podem ser citados os municípios e as bacias hidrográficas (MAGALHÃES JÚNIOR, 2007). Nesse processo, tal como os princípios da legislação francesa, deve envolvera participação de diferentes setores da sociedade, incluindo os usuários da água e representantes da sociedade civil organizada (BERRETA, 2012).

As primeiras iniciativas de organização e instalação de comitês de bacias hidrográficas, conforme observado por Berreta (2012),ocorreram no Rio Grande do Sul, em 1988, com os órgãos colegiados das bacias dos rios Sinos e Gravataí, efetivadas a partir da articulação de representações da comunidade local e o apoio do governo estadual. Nos anos seguintes, outras experiências são postas em prática por meio dos projetos pioneiros de gestão de bacias nacionais, entre os quais se destacam as experiências nas bacias dos rios Doce (a

\footnotetext{
Órgão gestor de recursos hídricos de Mato Grosso do Sul.
} 
partir de 1989) e Paraíba do Sul (a partir de 1992), como destacado por Formiga-Johnsson et al. (2007)e Ioris, $(2009,2013)$. No ano de 1991, destaca-se a criação dos comitês de bacias do Alto Tietê e dos rios Piracicaba, Capivari e Jundiaí (CBH- PCJ), ambos localizados no estado de São Paulo (PEREIRA; JOHNSSON, 2005; MIRANDA, 2006).

A partir da promulgação da Lei federal 9.433 de 1997instituiuaPolítica Nacional dos Recursos Hídricos, criou o Sistema de Gerenciamento dos Recursos Hídricos e os comitês de bacia hidrográfica compreendidos como órgãos colegiados locais cujas atribuições devem ser exercidas na bacia hidrográfica de sua jurisdição(BRASIL, 2006).

Conforme observado por Pereira e Johnsson (2005), para efetivar o funcionamento do sistema de gerenciamento, paralelamente, foram adotados ajustes políticos-institucionais e a criação de órgãos diretamente ligados ao Governo federal, tais como: o Conselho Nacional de Recursos Hídricos (CNRH), que tomou posse em 1998, e a Agência Nacional de Águas (ANA) - aprovada no ano 2000 por meio da Resolução do CNRH que estabelece as diretrizes gerais para a formação e funcionamento dos Comitês de Bacias Hidrográficas. A ANA foi instituída como entidade federal com a função de implementar a Política Nacional de Recursos Hídricos e de coordenar o Sistema Nacional de Gerenciamento de Recursos Hídricos (SINGREH). Com a aprovação da Lei No 9.984/00, ficou estabelecido o conjunto de regras para a sua atuação, sua estrutura administrativa e suas fontes de recursos. Entre as fontes de arrecadação de receita da ANA, foram incluídos os recursos decorrentes da cobrança pelo uso de água de corpos hídricos de domínio da União (BRASIL, 2000).

Nas últimas décadas, visando atender a referida Lei federal, observa-se as ações de apoio à formação e instituição de comitês de bacias nas esferas:federal e estaduais. Associado às metas dessa Política, o número de novos comitês estaduais cresceu expressivamente, tanto que, a partir de 1997, o número de comitês de bacias instalados em rios de domínio estadual, passou de 29, naquele ano, para 194, em 2013, cobrindo, atualmente, quase 30\% do território nacional (BRASIL, 2014).

Segundo Abers e Jorge (2005) esse acelerado processo de instituição dos comitês deve, em parte, ao fato de que, no período entre 1991 e 1997, muitos estados já havia aprovadas suas legislações sobre recursos hídricos, como também, motivados pela lei federal, muitos estados passaram a adequar e promulgar suas leis de recursos hídricos e criar novos comitês.

Nas duas últimas décadas, na maioria dos estados brasileiros já haviam institucionalizados órgãos colegiados de bacias hidrográficas. Enfatiza-se que os estados com o maior número de comitês são Minas Gerais, São Paulo, seguido do Rio Grande do Sul, figura 1. Destaca-se, ainda, que nessa última década foram formados novos comitês, entre 
esses se encontram os sul-mato-grossenses, o comitê federal do rio Paranaíba (instituído ano de 2008); e o comitê do rio Miranda, criado no ano 2005 foi criado, e o comitê do rio Ivinhema, formado no ano de 2010, apresentados na figura 2.

Figura 1. Distribuição dos comitês estaduais de bacias hidrográficas no território brasileiro.

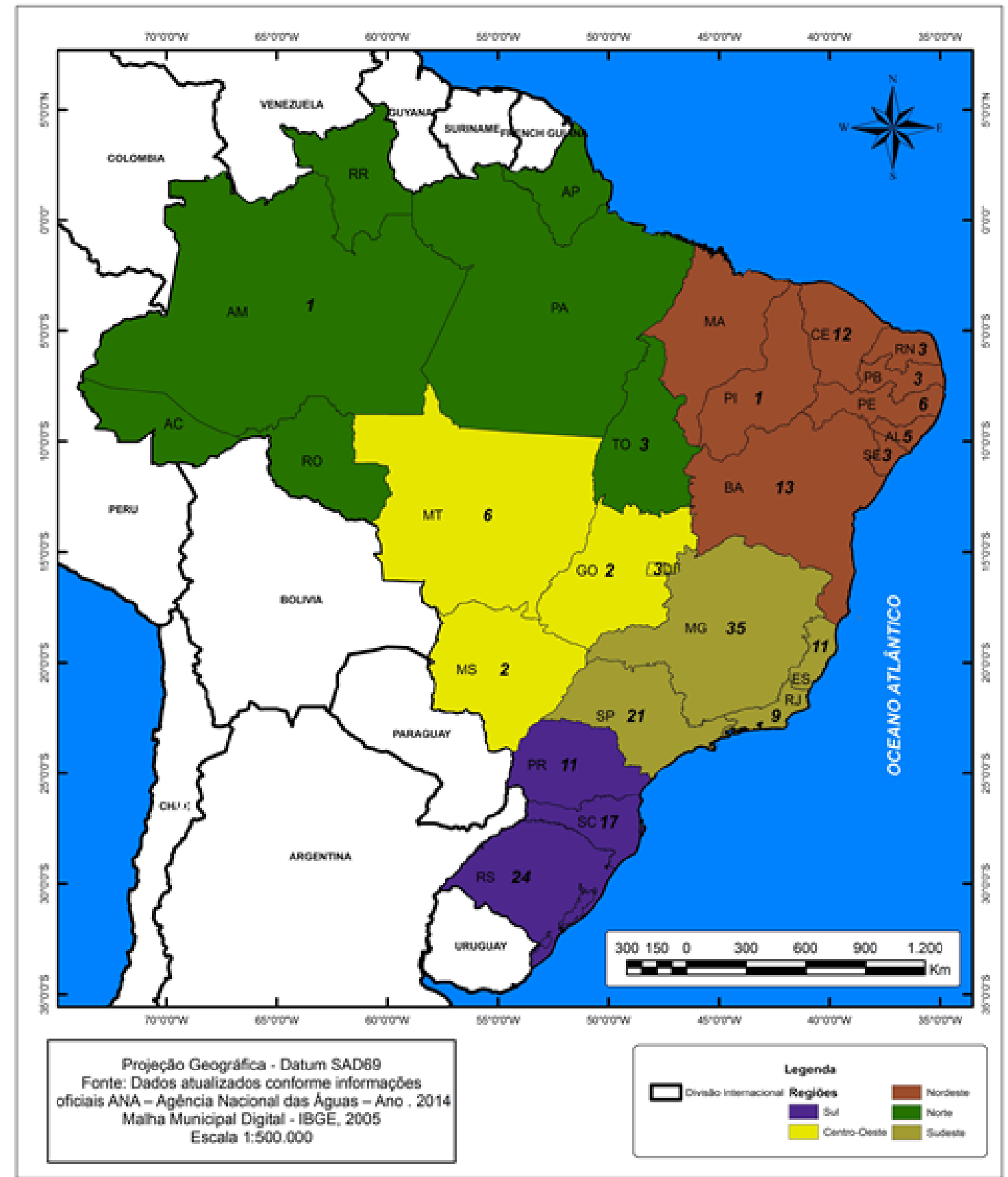

Fonte: elaboração dos autores a partir dos dados da Agência Nacional das Águas (BRASIL, 2014). 
Figura 2. Comitês de bacias hidrográficas instituídos no Mato Grosso do Sul

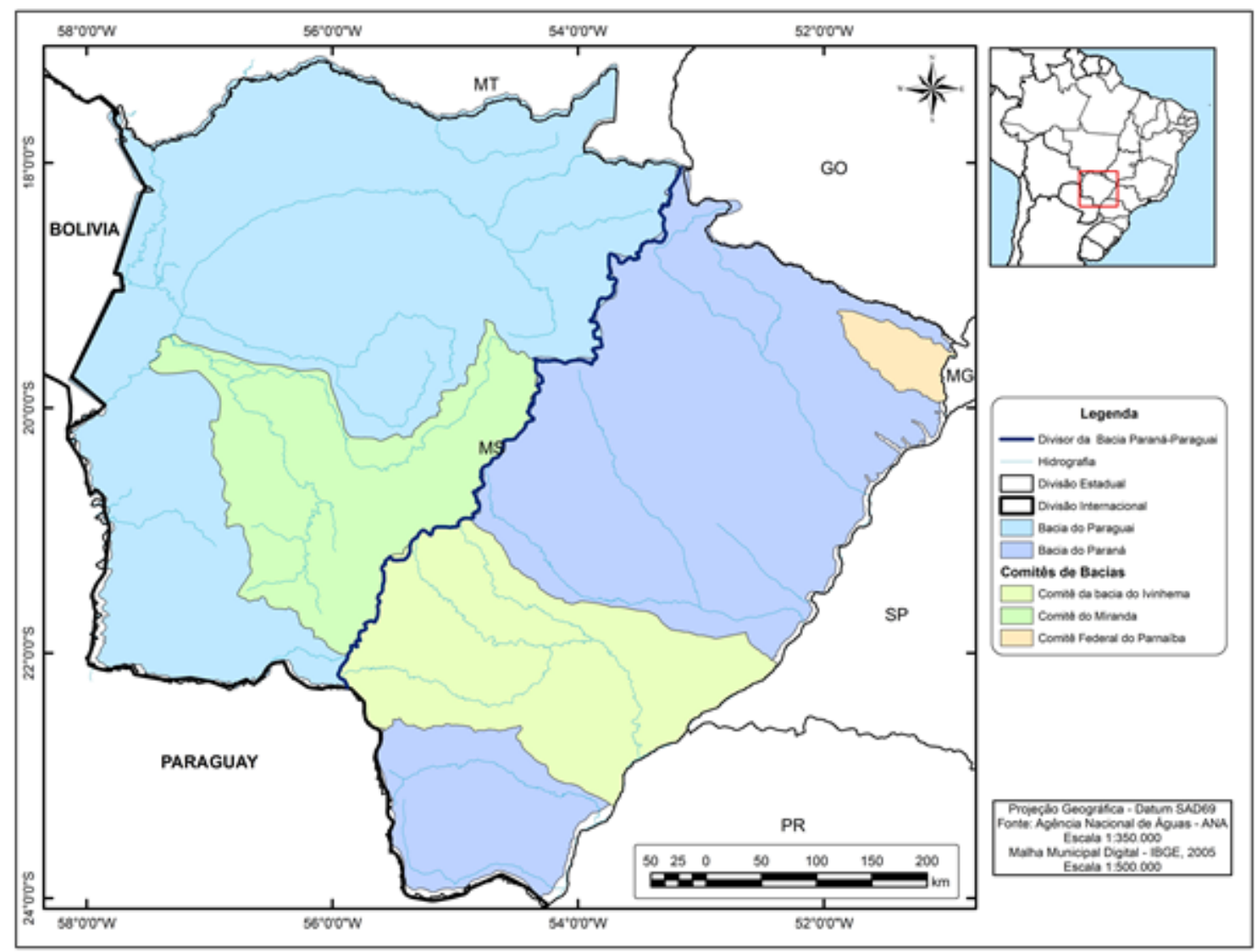

Fonte: elaborado pelos autores a partir dos dados disponibilizados pelo Instituto de Meio Ambiente de Mato Grosso do SUI (MATO GROSSO DO SUL, 2014).

\section{OS COMITÊS DE BACIAS HIDROGRÁFICAS: FORMALIDADES E DESAFIOS}

No território brasileiro, considerando o período entre 1997 até 2014, foram criados nove comitês interestaduais, entre os quais se encontram: Paraíba do Sul, São Francisco, PCJ - (Piracicaba, Capivari e Jundiaí), rio Doce, Verde Grande, Piranhas-Açu, Paranaíba, rio Grande e o rio Paranapanema. Foram criados mais de duzentos comitês de bacias hidrográficas, entre interestaduais e estaduais (BRASIL, 2014).

Conforme os dados apresentados pela Rede Brasil de Organismos de Bacia Hidrográfica² ${ }^{2}$ até 2014, mais de 220 comitês foram criados em 20 Estados da Federação. Em 2013, foram instalados 20 novos comitês nos estados da Bahia, Ceará, Goiás, Mato Grosso, Paraná, Rio Grande do Norte e Santa Catarina (BRASIL, 2014). Na região Norte,foram instalados quatro comitês, e, nos estados do Pará, Amapá, Roraima, Rondônia e Acre não há registros de implantação de colegiados de bacias.

Disponível em:<http://www.rebob.org.br/>Acesso em: 15 jun. 2015. 
Em relação à distribuição regional dos comitês de bacias, o maior número de organismos de bacias criados no país, até o momento, encontra-se nas regiões Sudeste, Sul e Nordeste. Nas regiões Norte e Centro-Oeste, os aparatos institucionais de política de Estado na criação dos comitês em escala de bacias hidrográficas são mais recentes e apresentam assimetrias, poucos comitês foram criados, sendo inexistentes em muitos estados.

A criação dos organismos de bacias ocorre com múltiplas lógicas, mas, de modo geral, são criados em bacias hidrográficas identificadas como estratégicas, principalmente, do ponto de vista social, ambiental e econômico, particularmente,onde se verificam situações de disputas entre os setores produtivos e crescente apropriação dos recursos hídricos(FORMIGA-JOHNSSON et al. 2007).Nestes casos, situa-se a maioria dos comitês federais interestaduais institucionalizados por Decretos do Governo federal, visando estabelecer normas e controles de usos e exploração dos recursos hídricos. São alguns desses colegiados os comitês do rio Doce, Paraíba do Sul e do Piracicaba, Capivari e Jundiaí (PCJ), que passaram por alterações de legislações e área de jurisdição, sendo considerados como comitês interestaduais.

Os comitês de bacias hidrográficas são órgãos que possuem as competências de,entre outras, promover o debate, intervir e arbitrar e resolver os conflitos, em primeira instância, entre os usuários, a sociedade civil e o poder público de questões relacionadas aos recursos hídricos. Ainda cabe aos comitês, o papel de discutir e deliberar sobre a elaboração do Plano de Recursos Hídricos da bacia, bem como acompanhar sua execução e sugerir as providências necessárias ao cumprimento de suas metas. Além disso, devem: prevê a outorga, o direito de usos dos recursos hídricos, discutir e aprovar a implantação dos mecanismos de cobrança pelo uso da água (BRASIL, 2006).

Em relação ao mecanismo de cobrança pelo uso da água enfatiza-se que nos rios de domínio da União às arrecadações dos recursos financeiros advindos dessa cobrança deverão ser integralmente repassados pela Agência Nacional das Águas (ANA) às entidades delegatórias de funções da agência de água da bacia em que os recursos foram gerados. Nos estados, os recursos devem ser repassados as agências de água local, com destinação de aplicação nas ações de planejamento e gestão da bacia hidrográfica, conforme deliberações dos seus respectivos comitês (BRASIL, 2014). Portanto, cabe aos membros representantes dos comitês de bacia hidrográfica articular-se para tomada de decisões nas destinações desses recursos públicos.

Contudo, deve ser ressaltado que os comitês de bacias hidrográficas estão em processo de consolidação e, até momento, há obstáculos e desafios,sobretudo, nas regiões com problemas associados à escassez hídrica e/ou acesso de água potável. Nestes 
comitês,conforme analisado por Ioris (2013),surgem entre as representações setores interessados em deter o controle de decisões, bem como há outros que buscam manter uma pressão sobre os órgãos fiscalizadores dos mecanismos de gestão dos recursos hídricos.

Para Magalhães Júnior (2007), e Leal (2012) entre os desafios para a operacionalização dos comitês de bacias nacionais está na definição e sobreposição das bacias hidrográficas formadas por rios de domínios estaduais e federal, como também na compatibilização da gestão em um sistema federativo no qual as metas dessa política nem sempre converge com as demais políticas ambientais estaduais e municipais.

Além disso, ainda devem ser observadas outras especificidades, por exemplo, na região Nordeste onde a rede hidrográfica possui muitos rios intermitentes, obras de engenharia como os açudes, cisternas que reforça o surgimento das associações de usuários reunidas como modo alternativo para uma gestão participativa(PAGNOCCHESCHI, 2003).

Ao observar outros exemplos como, localidades onde há obras de engenharia como os reservatórios para geração de energia elétrica e abastecimento público urbano, bem como as reversões e transposição de bacias, especialmente para esses casos, os comitês ou as associações precisam de outra perspectiva conceitual de unidade física-territorial para a gestão dos recursos hídricos. Outra questão de ordem técnica e prática diz respeito, por exemplo, aos dados socioeconômicos, censitários e de infraestrutura que são coletados e apresentados em escala municipal, nesses casos, não estão associados aos limites de bacias hidrográficas, portanto, na aplicação de métodos de sobreposição de dados às análises podem ficar fragilizadas.

$\mathrm{Na}$ mesma perspectiva, ao considerar as atuais demandas de usos dos recursos hídricos aponta-se que ao longo do século XX muitos dos avanços técnico-científicos ampliaram as possibilidades de usos dos recursos hídricos, como por exemplo, a irrigação, os represamentos, as transposições de bacias, a dessalinização e as chuvas artificiais. Em relação a esses avanços, merecem uma atenção no que diz respeito a suas implicações negativas no acesso social e comum dos recursos hídricos (BEZERRA, 2011).

Ainda associada às essas implicações, Di Mauro (2012) alerta sobre as manipulações químicas, por exemplo, utilizadas na produção de sementes modificadas (transgênicas) e dos agroquímicos que apresentam algum tipo de incerteza sobre:

[...] os riscos que poderão ocasionar para a saúde humana e para o meio ambiente, devem ser adotadas medidas de prevenção para restringir seu uso, até que sejam apresentadas as comprovações sobre suas consequências. Aqueles que produzem essas mercadorias devem ficar com a obrigação de comprovar tal sanidade e se responsabilizar pelas consequências adversas que porventura aconteçam (DI MAURO, 2012, p.33). 
Não se trata de negar os avanços tecnológicos, pois há alternativas importantes, tais como, a filtragem e reutilização de águas servidas, equipamentos de redução do consumo e perdas nos sistemas de abastecimento ${ }^{3}$, o uso e tratamento das captações de águas pluviais, entre outras, devem ser reconhecidas e aplicadas como alternativas viáveis no âmbito social, econômico e ambiental. Por esses motivos, conforme observa Moretti (2012), é necessário refletir sobre a ideia dominante da credibilidade máxima no desenvolvimento técnico-científico para as resoluções dos problemas como uma questão de tempo. Em contraponto, no interior do capital, as técnicas não são acessíveis a todos, mas, sim, aos que podem pagar por elas.

Destacam-se também as situações dos rios amazônicos e do pantanal, como organizar ou articular comitês em escala de bacias? Tendo em vista a necessidade de identificar os atores sociais que, diretamente ou indiretamente, tradicionalmente utilizam das águas para as suas necessidades básicas e, ainda, como promover, organizar e incluir no debate e no processo de tomada de decisões os atores usuários das águas das comunidades tradicionais, por exemplo, os ribeiros, pescadores, povos indígenas, como na experiência do $\mathrm{CBH}-\mathrm{Miranda}$ em que muitas das situações de disputas pelo acesso ao uso dos recursos hídricos transcendem ao local da bacia hidrográfica do rio Miranda o qual o comitê foi criado e coordena.

Nesse sentido, ao refletir sobre qual o papel dos comitês de bacia hidrográfica observase que, em muitos momentos, há outros significados, transformando-se em disputas pelo controle político-institucional nos espaços de tomada de decisões. Nesses casos, parece razoável admitir limitações e desafios aos comitês de bacias hidrográficas existentes e aos que estão sendo criados, pois há disputas setoriais na aplicação de investimento financeiro na execução das ações previstas nos planos de bacias que, muitas vezes, são em favor de interesses econômicos e da iniciativa privada (MARINHO, MORETTI, 2013).

\section{A BACIA HIDROGRÁFICA DO RIO MIRANDA}

Abacia do rio Miranda drena uma extensão territorial de $43.787 \mathrm{~km}^{2}$, com as coordenadas $19^{\circ} 15^{\prime} 00^{\prime \prime}$ e $22^{\circ} 00^{\prime} 00^{\prime \prime}$ de Latitude Sul e $54^{\circ} 15^{\prime} 00^{\prime \prime}$ e $57^{\circ} 30^{\prime} 00^{\prime \prime}$ de Longitude Oeste, inserida integralmente nos limites brasileiros na região Centro-Oeste. Considerando sua inserção regional, a bacia encontra-se inserida na Bacia do Paraguai, nas depressões situadas no extremo sudoeste do Mato Grosso do Sul, limita-se a leste pela Serra de Maracaju e a oeste pela Serra da Bodoquena(MATO GROSSO DO SUL, 2010).

3 Os dados disponibilizados pelo Sistema Nacional de Informações Sobre Saneamento (SNIS) apontam que, em geral, no Brasil os sistemas de abastecimento de água tratada apresentam elevados índices de perdas. 
A bacia do rio Miranda apresenta uma grande variabilidade litológica e estrutural. As características geológico-paleontológicas presentes são de significativa importância científica, raridade e beleza cênica. Associadas a tais particularidades ocorrem feições de rochas cársticas, onde atualmente são exploradas por diversas atividades econômicas, por exemplo, nas proximidades da cidade de Bodoquena, Bonito e Jardim. Nestes municípios os afloramentos carbonático sem contato a água propicia a origem de inúmeras cavernas, dolinas, ressurgências e sumidouros, entre outras feições, favoráveis á exploração espeleológicas em grutas e cavernas de excecional beleza. Além desses elementos, somamse outros, a exploração dos rios Formoso e Salobra, entre outros onde as suas águas de aspecto cristalino são recursos explorados por empreendimentos privado do setor turístico.

De acordo com resultados apresentados no documento do Plano de Recursos Hídricos da Bacia do Rio Miranda, elaborado entre o período de 2013-2014, a bacia hidrográfica do rio Miranda apresenta como principais destinações dos usos e demandas das águas as atividades de pecuária,agrícola e o abastecimento humano (MATO GROSSO DO SUL, 2014).

Conforme os estudos realizados por Pereira, et. al. (2004) e os relatórios da Conjuntura de Recursos Hídricos no Brasil, elaborado pela ANA (BRASIL, 2013; 2014), constouse que nessa bacia hidrográfica, especialmente, no seu alto curso e principais nascentes, localizadas na Serra de Maracaju, observa-se que as formas de exploração agrícola, com cultivos da soja e, mais recentemente, cana-de-açúcar, associados à aplicação intensiva de fertilizantes e agrotóxicos podem comprometer, em curto espaço tempo, as águas superficiais e as reservas subterrâneas. Situação semelhante ocorre nos setores de cabeceiras do rio Aquidauana, porém os problemas são associados à atividade da suinocultura e pelo avanço dos processos erosivos como, por exemplo, os que ocorrem no município de São Gabriel do Oeste(MATO GROSSO DO SUL, 2014).

Ao tratar sobre o consumo de água destinada à agricultura, Ribeiro (2008) ressalta que os sistemas produtivos agrícolas demandam cerca de $70 \%$ da água coletada no mundo. Corroborando, Bezerra (2011) alerta, na atualidade a produção agrícola global é a atividade produtiva que mais consome água, com indicação evolutiva, devido ao avanço das fronteiras do agronegócio em regiões que, antes consideradas impróprias ás lógicas agroindustriais, através da aplicação de tecnologias de correção de solos e de irrigação são incorporados aos novos territórios da produção.

Com essa prerrogativa e, em atendimento à Política Nacional de Irrigação (LeiN. 12.787) no ano de 2013, o Estado do Mato Grosso do Sul, juntamente com os estados de Minas Gerais e Rio Grande do Sul elaboraram estudos para definição dos territórios da 
irrigação. No Mato Grosso do Sul foi instituído por meio do Decreto Estadual No 13.757 de 2013 a elaboração do Plano Diretor de Irrigação partir das Bacias Hidrográficas do Mato Grosso do Sul, os trabalhos foram realizados pelo Consórcio Irriga Mato Grosso do Sul (MATO GROSSO DO SUL, 2013).

Integrada a esse Plano, a participação dos comitês é prevista como estratégica por se constituírem numa instância de governança com capacidade potencial de ação na medida em que podem tornar efetiva a prerrogativa legal dos instrumentos de gestão, particularmente, a outorga e o mecanismo de cobrança dos usos recursos hídricos no Estado.

Conforme os estudos realizados por Thomaz Júnior (2010, p.11-12) cerca de “[...] $65 \%$ a $70 \%$ do da água alimentam os pivôs-centrais", cujos territórios estão associados ao avanço do agronegócio e sinaliza a dinâmica de expansão de novas áreas irrigadas no país. Portanto, é preciso ter cautela, contextualizando o Mato Grosso do Sul, a criação dos territórios da irrigação pode, em primeira instância, se configurar disputas de apropriação sobre os usos das águas em sistema intensivo voltado para a produção de commodities agrícolas e não agrícola para o mercado externo.

Desse modo, a discussão merece cautela quanto ao papel dos comitês de bacia hidrográfica como possuidores de legitimidade para mediar conflitos, pois são latentes nesses colegiados os diferentes de setores econômicos, grupos empresariais e agentes sociais representantes de instâncias de poder local e internacional com interesses em deter o conhecimento e controle nas definições das ações de gestão dos recursos hídricos das bacias hidrográficas.

\section{A EXPERIÊNCIA DO COMITÊ DE BACIA DO RIO MIRANDA}

A Política Estadual de Recursos Hídricos foi instituída pela Lei № 2.406 de 2002 a qual prevê juridicamente a criação dos comitês de bacias hidrográficas como integrantes do Sistema Estadual de Gerenciamento de Recursos Hídricos (MATO GROSSO DO SUL, 2002).

No Estado de Mato Grosso do Sul foram criados o comitê federal do rio Paranaíba, instalado em 2008, e dois comitês estaduais: o Comitê Estadual Rio Miranda, criado pela Resolução CERH No 002/2005, o Comitê Estadual Rio Ivinhema, criado por meio de Resolução do CERH/MS No 013/2010,e, ainda em discussão, a criação do Comitê do Rio Pardo (MATO GROSSO DO SUL, 2010).

A criação do Comitê de Bacia Hidrográfica do Rio Miranda resulta das ações realizadas desde 2001, na ocasião,em parcerias envolveram-se: a ONG WWF-Brasil e a Secretaria de 
Estado do Meio Ambiente de Mato Grosso do Sul (SEMA) ${ }^{4}$ e do Instituto Meio Ambiente Pantanal (IMAP), atualmente Secretaria de Estado do Meio Ambiente, do Planejamento, da Ciência e Tecnologia (SEMAC) e o Instituto de Meio Ambiente de Mato Grosso do Sul (IMASUL), o Consórcio Intermunicipal para o Desenvolvimento Integrado das Bacias dos Rios Miranda e Apa (CIDEMA), a Secretaria de Recursos Hídricos (SRH) do Ministério do Meio Ambiente (MMA) (PEREIRA, et. al. 2004).

Além desses atores - representados pelo poder público e entidades da sociedade civil, envolvidos diretamente na criação do CBH-Miranda, enfatizam-se os interesses em acompanhar e participar por representações de Associações e Sindicatos compreendidas, conforme a Lei estadual, como entidades regional, locais ou setoriais legalmente constituídas dos usuários de recursos hídricos da bacia.

Entre os resultados apresentados à sociedade,no ano 2003, constam a realização de estudos e a publicação do Estado da Arte do Miranda, documento divulgado e discutido em workshop, realizado em Bonito/MS, sendo, posteriormente encaminhado aos órgãos públicos oficiais visando subsidiar ações sobre a gestão da bacia hidrográfica do Rio Miranda, entre essas, a recomendação de criar o Comitê do Rio Miranda, efetivado dois anos mais tarde, no ano de 2005, após a aprovação do Conselho Estadual de Recursos Hídricos-CERH (PEREIRA, et. al, 2004).

O Ato jurídico da criação do CBH- Miranda foi por meio da Resolução de CERH/ MS N. 002 de 25/10/2005. Nessa ocasião, no Estado de Mato Grosso do Sul, havia sido recentemente instituída a Lei № 2.406/2002 que institui a Política Estadual de Recursos Hídricos, portanto, as ações para instalar esse Comitê foram realizadas no âmbito da implementação da primeira fase dessa Política de Governo.

O Comitê do rio Miranda consiste em um órgão colegiado deliberativo e normativo no âmbito da respectiva bacia hidrográfica, vinculado ao Conselho Estadual de Recursos Hídricos (CERH).No total, a área de jurisdição do $\mathrm{CBH}$ - rio Miranda representa aproximadamente $12 \%$ do território do Mato Grosso do Sul, onde, de forma total ou parcial, encontram-se localizados vinte dois municípios, a saber: Anastácio, Aquidauana, Bandeirantes, Bonito, Bodoquena, Campo Grande, Corguinho, Corumbá, Dois Irmão do Buriti, Guia Lopes da Laguna, Jaraguari, Jardim, Maracaju (pertencente aos comitês Miranda e Ivinhema), Miranda, Nioaque, Ponta Porã, Porto Murtinho, Rochedo, Rio Negro, São Gabriel d’Oeste, Sidrolândia e Terenos (MATO GROSSO DO SUL, 2010, 2014).

${ }^{4}$ A Secretaria de Estado de Meio Ambiente de Mato Grosso do Sul - SEMA foi criada em 1999. (Lei Estadual nº 1.940 , de $1^{\circ}$ de janeiro de 1999). 
A composição das representações do Comitê Rio Miranda consiste no número máximo de trinta e três membros titulares, com onze representantes por cada segmento. As representações devem ser compostas: da União, do Estado, dos Municípios situados, no todo ou em parte, em sua área de atuação; dos usuários das águas de sua área de atuação e das entidades civis de recursos hídricos com atuação comprovada na bacia. Destas representações, conforme previsto no Regimento Interno, muitas, até o momento, não possuem seus representantes de modo formalizado.

Noacompanhamento das atividades deste Comitê(gestão 2010-2014) é possível identificar como representações mais atuantes o poder público estadual representado pelo Instituto de Meio Ambiente de Mato Grosso do Sul(IMASUL), e a de usuários,direto ou indireto, das águas superficiais e/ou subterrâneas existentes na bacia. Entre essas, destacamse as representações dos setores de prestadores serviços diretamente ou indiretamente nas áreas de abastecimento de água e esgotamento sanitário a Empresa de Saneamento do Estado de Mato Grosso do Sul (SANESUL), a de energia elétrica a Empresa Energética de Mato Grosso do Sul (ENERSUL), e a industrial por meio da Federação das Indústrias do Estado de Mato Grosso do Sul (FIEMS), os sindicatos e associações de agricultores rurais, irrigantes e pecuaristas. Nas últimas gestões do CBH-Miranda, a Federação da Agricultura e Pecuária de Mato Grosso do Sul (FAMASUL) e setores de irrigação e pecuária ocupam os cargos de dirigentes, a saber, presidente e vice-presidente.

As entidades da sociedade civil possuem representações distribuídas de acordo com as seguintes categorias: consórcios e associações intermunicipais de bacias hidrográficas, organizações técnicas de ensino e pesquisa com interesse e atuação na área da bacia, organizações não governamentais com objetivos, interesses e ações de projetos na área de recursos hídricos e as comunidades indígenas residentes na bacia.

Em relação às representações de usuários das águas da bacia, são previstas as representações pelos segmentos de abastecimento urbano, indústrias, irrigação, agropecuário, hidroviário, pesca, turismo e lazer e o setor energético.

Nesse colegiado, são tímidas e/ou não se fazem presentados nas decisões e ações desse comitê os setores de usuários de como, pequenos agricultores e comunidades tradicionais, entre eles, ribeirinho, pescadores, quilombolas e povos indígenas, que vivem na área de jurisdição do $\mathrm{CBH}$-Miranda. Com relação à última, em Regimento Interno do Comitê prevê a garantia de participação e representação pela Fundação Nacional do Índio - FUNAI e das comunidades indígenas residentes na área de atuação, porém, até o momento, isto ocorre apenas como indicação. 
Ao analisar refletir sobre a multiplicidade das relações e dos sujeitos na construção desse territóriotais representações assumem relevância e devem ser observado no Comitê e no seu Plano de Bacia. No nosso acompanhamento das reuniões de consulta pública as quais foram realizadas durante a elaboração desse documento, observou-se a fragilidade dos processos participativos, tanto no debate quanto na articulação e participação dos grupos sociais residentes na bacia hidrográfica do rio Miranda.

Considerando os instrumentos de gestão como, por exemplo, a aprovação dos planos de recursos hídricos, a outorga e o mecanismo de cobrança da água, bem como a aplicação de recursos na bacia, conforme previstas pela política de Estado, se o processo de tomada de decisões foi apropriado por grupos dominantes locais e interesses privados internacionais. Diante do exposto, na construção de um debate visando à democratização de acesso à águaé inegável relevânciadasdiscussões sobre as experiências dos órgãos colegiados de bacia hidrográficaque, se por um lado, pode enriquecer o processo participativo local, mas por outro lado,revela o seu papel de tornar legítima perante a sociedade às normas de controles de usos e valoração econômica dos recursos hídricos. Por essas razões, indica-se que tais questões na prática transcendem aos limites e fronteiras da unidade-físico territorial da bacia hidrográfica o qual o Comitê foi criado e coordena.

\section{CONSIDERAÇÕES FINAIS}

O tema da gestão dos recursos hídricos reflete disputas de natureza políticoinstitucional, econômico e socioambiental. Envolve, por exemplo, polêmicas na materialização das ações no controle sobre da gestão dos recursos hídricos como uma política de Estado e os interesses dos setores de usuários da iniciativa privada que atuam nos comitês de bacias hidrográficas. A proposta contida na atual política de recursos hídricos elenca, entre as prioridades, o apoio e fortalecendo da institucional desses órgãos colegiados gestores de bacia hidrográfica no país.

O artigo apresenta o resultado de reflexões teóricas e pesquisa empírica realizada a partir de diálogos com gestores e pesquisadores. Entre os procedimentos metodológicos adotados, enfatiza-se o acompanhamento e os diálogos com sujeitos que vivenciam as práticas nos processos participativos nos comitês de bacias hidrográficas, com enfoque específico na vivência do CBH-Miranda, localizado no território sul-mato-grossense. Nesse processo, destaca-se que a troca de experiências cotidianas, muitas vezes, ultrapassam nossas concepções e interpretações do domínio acadêmico, porém, são fundamentais para enriquecer e qualificar o debate na academia e fora dela. 
Em relação àcriação dos comitês de bacias hidrográficas, foram contextualizados os comitês criados no Mato Grosso do Sul tratando, em particular, o Comitê de Bacia Hidrográfica do Rio Miranda.Ao refletir sobre o papel desse colegiado gestor de recursos hídricos pode ser compreendido instância política-institucional inseridos em processo de legitimação da valoração, controle de usos e apropriação dos recursos hídricos.

Os resultados dessa pesquisa sinalizam uma multiplicidade de implicações na democratização de acesso aos usos das águas e que, indiretamente, envolvem nas políticas de gerenciamento de recursos hídricos os órgãos colegiados de bacia hidrográfica cujo papel na mediação de conflitos podem levar reafirmar os interesses dos diferentes grupos e agentes sociais usuários das águas da bacia. Desse modo, no processo que levou a instalação do $\mathrm{CBH}-$ Miranda, congregaram várias instituições organizadas em torno de interesses próprios, o que prática repercute em alianças entre as metas de execução de uma Política de Governo (Federal e Estadual) e de grupos da sociedade civil com interesses econômico e privado, como também de setores financeiros internacionais por fornece meios - créditos e empréstimos, que de forma estratégica tem promovido o controle dos usos, exploração e apropriação mercantil dos recursos hídricos.

\section{REFERÊNCIAS}

1. BERRETA, Márcia dos Santos Ramos; LAURENT, François; BASSO, Luís Alberto. Os princípios e fundamentos da legislação das águas na França. Boletim Gaúcho de Geografia,n. 39, p. 13 24, jul. 2012.

2. BEZERRA, João Paulo Peres. A água como elemento estruturante na construção de territórios da soberania alimentar. Presidente Prudente:NERA - Núcleo de Estudos, Pesquisas e Projetos de Reforma Agrária. DATALUTA, p.1-17, 2011.

3. BRASIL (República Federativa do Brasil). LEI 9.433, de 8 de janeiro de1997. Institui a Política Nacional de Recursos Hídricos, cria o Sistema Nacional de Gerenciamento de Recursos Hídricos,regulamenta o inciso XIX do art. 21 da Constituição Federal, e altera o art. $1^{\circ}$ da Lei no 8.001, de 13 de março de 1990, que modificou a Lei nº 7.990, de 28 de dezembro de 1989. Brasília, DF, 1997.

4. BRASIL. (República Federativa do Brasil). Plano Nacional De Recursos Hídricos: Prioridades 2012-2015.Brasília: Ministério Do Meio Ambiente (MMA). Secretaria de Recursos Hídricos e Ambiente Urbano (SRHU). Agência Nacional de Águas (ANA),2011. 119p.

5. BRASIL. (República Federativa do Brasil). Resolução No 12, de 19 de Julho de 2000. Brasília: Conselho Nacional De Recursos Hídricos (CNRH), D.O.U de 20 de julho de 2000. 
6. BRASIL. (República Federativa do Brasil). Resolução № 5 de $\mathbf{1 0}$ de Abril de 2000. Brasília: Conselho Nacional De Recursos Hídricos (CNRH), 2000. Disponível em: <file://D:/Dados/ Downloads/resolucao_05-.pdf> Acesso em: 23 maio 2015.

7. BRASIL. (República Federativa do Brasil). Conjuntura dos recursos hídricos no Brasil: 2013. Brasília: Agência Nacional de Águas (ANA) 2013. 432.p.

8. BRASIL. (República Federativa do Brasil). Conjuntura dos recursos hídricos no Brasil: informe 2012. Ed. Especial. Brasília: Agência Nacional de Águas (ANA), 2012. 215 p.

9. BRASIL. (República Federativa do Brasil). Plano Nacional De Recursos Hídricos. Síntese Executiva. Brasília: Ministério Do Meio Ambiente (MMA), Secretaria De Recursos Hídricos (SRH), 2006. 135p.

10. BRASIL. ANA - Agência Nacional de Águas. Conjuntura dos recursos hídricos no Brasil: regiões hidrográficas brasileiras - Edição Especial. Brasília: ANA, 2014. Disponível em: <http://conjuntura.ana.gov.br/docs/regioeshidrograficas.pdf>. Acesso em: 22 nov. 2014.

11. DI MAURO, Cláudio Antônio. Construção da nova democracia ambiental: democracia sem fim. Boletim Campineiro de Geografia. v.2, n.1. 2012, p. 27-36.

12. DI MAURO, Cláudio Antônio; ROSOLEN, Vânia, FERREIRA; Vanderlei de Oliveira (Org.). Planejamento e gestão de recursos hídricos: exemplos mineiros. Uberlândia: Assis Editora, 2012, 454p.

13. FERRAZ, Cláudio Benito Oliveira. O estudo geográfico dos elementos culturais. Considerações para além da geografia cultural. Presidente Prudente: Terra Livre, Ano 23, v. 2, n. 29 p. 2950 Ago-Dez/2007.

14. FORMIGA-JOHNSSON, R. M.; KUMLER, L.; LEMOS, M. C. The politics of bulk water pricing in Brazil: lessons from the Paraiba do Sul Basin. Water Policy, v. 9, n. 1, p. 87-104, 2007.

15. IORIS, Antônio Augusto Rossotto. Desenvolvimento nacional e gestão de recursos hídricos no Brasil. Revista Crítica de Ciências Sociais, 85, p. 23-41, jun. 2009.

16. IORIS, Antônio Augusto Rossotto. Na contracorrente dos rrecursoshhídricos. Água ambiente no Brasil Contemporâneo. Edimburgo: 2013.176p.

17. MAGALHÃES JÚNIOR, Antônio Pereira. Indicadores ambientais e recursos hídricos:realidade e perspectiva para o Brasil a partir da experiência francesa. Rio de Janeiro: Bertrand, 2007.686p.

18. MARINHO, Vera Lúcia Freitas; MORETTI, Edvaldo Cesar. Os caminhos das águas: As políticas públicas ambientais e criação dos Comitês de Bacias Hidrográficas. Florianópolis: Geosul, v. 28, n. 55, p 123-142, jan./jun. 2013.

19. MATO GROSSO DO SUL (Estado). Lei No 2.406, de 29 de janeiro de 2002. Institui a Política Estadual dos Recursos Hídricos, cria o Sistema Estadual de Gerenciamento dos Recursos Hídricos e dá outras providências. Campo Grande: D.O (MS), 30 de janeiro de 2002.

20. MATO GROSSO DO SUL (Estado). Plano Diretor de Irrigação nas Bacias Hidrográficas do Mato Grosso do Sul (PIBH/MS). Campo Grande: Instituto Interamericano de Cooperação para a Agricultura (IICA), Consórcio Irriga MS. 2013. Disponível em: $<$ http://ww1.imprensaoficial. ms.gov.br/pdf/DO8512_10_09_2013.pdf >Acesso em: 10 nov. 2013. 
21. MATO GROSSO DO SUL (Estado). Plano Estadual De Recursos Hídricos De Mato Grosso Do Sul - PERH. MS.Campo Grande: Secretaria de Estado e Meio Ambiente do Planejamento e da Ciência e Tecnologia (SEMAC), Instituto de Meio Ambiente de Mato Grosso do Sul (IMASUL), Editora da UEMS, 2010. 194.p.

22. MATO GROSSO DO SUL (Estado). Resolução $\mathrm{N}^{\circ}$ 002, de 23 de novembro de 2005.Campo Grande: Conselho Estadual de Recursos Hídricos, 2005.

23. MATO GROSSO DO SUL. (Estado). Plano de recursos hídricos da bacia hidrográfica do rio Miranda. Campo Grande: Instituto de Meio Ambiente de Mato Grosso do Sul (IMASUL), Deméter Engenharia Ltda. 2015. Disponível em:< https://sites.google.com/site/ prhbhmiranda/>Acesso em: $11 \mathrm{dez} 2015$.

24. MIRANDA, Cristiani Olga. O papel político-institucional dos comitês de bacia hidrográfica no estado de São Paulo: um estudo de caso. In: FELICIDADE, Norma; MARTINS, Rodrigo Constante; LEME, Alessandro André. (Coord.) Uso e gestão dos recursos hídricos no Brasil: velhos e novos desafios para a cidadania. São Carlos: RiMa, 2006, p. 136-148.

25. MOREIRA, Maria Manuela Martins Alves. A Política Nacional de Recursos Hídricos: avanços recentes e novos desafios. In: FELICIDADE, Norma; MARTINS, Rodrigo Constante; LEME, Alessandro André. (Coord.) Uso e gestão dos recursos hídricos no Brasil: velhos e novos desafios para a cidadania. São Carlos: RiMa, 2006, p. 69-75.

26. PAGNOCCHESCHI, Bruno. Política Nacional de Recursos Hídricos. In: LITTLE, Paul (Org.). Políticas ambientais no Brasil: análises, instrumentos e experiências. São Paulo: IIEB, 2003.p. 239-315.

27. PEREIRA, Mauri César Barbosa; MENDES, Carlos André Bulhões; GREDS, SandorArvino; BARRETO, Samuel Röiphe; BECKER, Michael; LANGE, Maria Bernadete Ribas; DIAS, Felipe Augusto. Bacia Hidrográfica do rio Miranda: estado da arte. Campo Grande: UCDB, 2004. 177p.

28. RIBEIRO, Wagner Costa. Geografia política da água. São Paulo: Annablume, 2008. 162p.

29. THOMAZ JÚNIOR, Antônio. Dinâmica territorial do Agrohidronegócio e os desdobramentos para o Trabalho. Revista OKARA: Geografia em debate. João Pessoa: v.6, n.1, p. 7-31, 2012.

Artigo recebido em 15 de outubro de 2015.

Artigo aceito 18 de abril de 2016. 